\title{
The Search for Molecular Markers in a Gene-Orphan Case Study of a Pediatric Spinal Cord Pilocytic Astrocytoma
}

\author{
CAROLINA MARTINELLI ${ }^{1 *}$, FABIO GABRIELE ${ }^{1 *}$, FEDERICO MANAI $^{1}$, ROBERTO CICCONE $^{2,3}$, \\ FRANCESCA NOVARA ${ }^{3}$, ELISABETTA SAUTA ${ }^{4}$, RICCARDO BELLAZZI ${ }^{4}$, MONICA PATANE $^{5}$, \\ ISABELLA MORONI ${ }^{5}$, ROSINA PATERRA ${ }^{5}$ and SERGIO COMINCINI ${ }^{1}$ \\ ${ }^{1}$ Department of Biology and Biotechnology, University of Pavia, Pavia, Italy; \\ ${ }^{2}$ Department of Molecular Medicine, University of Pavia, Pavia, Italy; \\ ${ }^{3}$ Microgenomics Laboratory, Pavia, Italy; \\ ${ }^{4}$ Department of Electrical, Computer and Biomedical Engineering, University of Pavia, Pavia, Italy; \\ ${ }^{5}$ Neuropathology Unit, Fondazione IRCCS Istituto Neurologico Carlo Besta, Milan, Italy
}

\begin{abstract}
Background/Aim: We herein presented a case of pediatric spinal cord pilocytic astrocytoma diagnosed on the basis of histopathological and clinical findings. Materials and Methods: Given the paucity of data on genetic features for this tumor, we performed exome, array CGH and RNA sequencing analysis from nucleic acids isolated from a unique and not repeatable very small amount of a formalinfixed, paraffin-embedded (FFPE) specimen. Results: DNA mutation analysis, comparing tumor and normal lymphocyte peripheral DNA, evidenced few tumor-specific single nucleotide variants in DEFB119, MUC5B, NUDT1, LTBP3 and CPSF3L genes. Differently, tumor DNA was not characterized by for the main pilocytic astrocytoma gene variations, including BRAFV600E. An inframe trinucleotides insertion involving DLX6 or Inc DLX6-AS1 genes was scored in $44.9 \%$ of sequenced reads; the temporal profile of this variation on the expression of DLX-AS1 was investigated in patient's urine-derived exosomes, reporting no significant variation in the one-year molecular follow-up. Array CGH identified a tumor microdeletion at the 6q25.3 chromosomal region, spanning 1,01 Mb and comprising ZDHHC14, SNX9, TULP4 and SYTL3 genes. The expression of these genes did not change in urine-derived exosomes during the one-year
\end{abstract}

This article is freely accessible online.

*These Authors contributed equally to this study.

Correspondence to: Dr. Sergio Comincini, Department of Biology and Biotechnology, University of Pavia, 27100 Pavia, Italy. Tel. +39 0382 985529, e-mail: sergio.comincini@unipv.it

Key Words: Pediatric astrocytic tumors, exome analysis, DNA mutations, chromosomal abnormalities, bioinformatics. investigation period. Finally, RNAseq did not reveal any of the common pilocytic BRAF-KIAA1549 genes fusion events. Conclusion: To our knowledge, the present report is one of the first described gene-orphan case studies of a pediatric spinal cord pilocytic astrocytoma.

Pilocytic astrocytoma (PA) is a World Health Organization (WHO) grade I tumor, accounting for approximately $25 \%$ of pediatric brain tumor patients and $1.5 \%$ of adult brain tumor patients with the incidence rate of 4.8 per million per year; these cancers occasionally affect the spinal cord (1). PA is generally considered to be a slow-growing, wellcircumscribed lesion, often containing cystic areas that can be surgically curable after a gross total resection $(2,3)$.

Spinal PA accounts for $21 \%$ of the intramedullary glial tumors that affect children and young adults and include primary and secondary spinal PA originated from dissemination of intracranial PA through cerebrospinal fluid (4-6). Primary spinal PA requires surgical resection similar to other intramedullary spinal tumors (7), but there is no clear evidence that adjuvant radio- and/or chemo-therapy treatments after surgery might be necessary. To date, only a few spinal cord PA, either case reports or sporadic ones, have been described in their genetic and molecular characteristic signatures (8-13). The most recurrent genetic alterations in WHO Grade I spinal cord astrocytomas are BRAF-KIAA1549 translocation, $B R A F$ copy number gain and the BRAFV600E single nucleotide variation. Additionally, these tumors displayed non-synonymous mutations in $N F 2$, NTRK1, NTRK3, PDGFRA and TP53 genes. However, according to current literature, $B R A F$ mutations, the evaluation of the mitotic index and p53 immunoreactivity did not have a statistically significant relationship with the prognosis (14).

As reviewed by Karsky and colleagues (15), some common mutations observed in cranial glioblastoma 
multiforme (GBM) specimens are also present in spinal astrocytomas, involving $C D K N 2 A, P T E N, B R A F, T P 53$ and $H 3 F 3 A$ genes. $C D K N 2 A$ encodes a cell-cycle regulatory protein and its mutations may result in unregulated cell proliferation. PTEN is involved in regulating phosphorylation of membrane-bound phosphatidylinositol, which influences downstream PKB/Akt signaling to induce cell proliferation, migration and mRNA translation. Importantly, numerous downstream targets from PTEN have been identified, such as mTOR and Akt proteins, and several chemical antagonists of these effector proteins are currently under clinical investigation for managing cranial astrocytoma, theoretically opening the possibility of expanding treatments to spinal cord astrocytoma. The BRAF gene has also been observed to be a target of different mutational events, particularly the BRAF-KIAA1549 fusion chimeric transcripts. Generally, BRAF alterations result in a constitutively active protein that promotes tumor formation. However, constitutive activation of BRAF has not been shown to consistently result in a poorer prognosis for patients with cranial and spinal astrocytomas $(16,17)$.

In this study, we reported a genetic characterization of a rare pediatric spinal cord pilocytic astrocytoma, with a fundamental absence of the above mentioned molecular signatures that might represent a starting point to next compare with similar clinical cases to find common genetic determinants.

\section{Materials and Methods}

Case description. An 8-year-old male was diagnosed as having spinal cord pilocytic astrocytoma (WHO I) through MRI imaging and histopathology of tissue sections at the neurosurgical Unit of Besta Institute (Milan, Italy). Before diagnosis, the patient documented a hypotrophy and hyposthenia condition localized at the right inferior leg. A single and not repeatable specimen of about $90 \mathrm{mg}$ was surgically removed from the dorsal lumbar region, formalin fixed, paraffin embedded (FFPE), and cut into 2-4 $\mu \mathrm{m}$ thick sections. For immunohistological analyses, slices were deparaffinized in xylene and rehydrated through decreasing concentrations $(100,95,90,80$ and $70 \%)$ of ethyl alcohol, then rinsed in distilled water. Antigen retrieval was performed in 0.01 $\mathrm{mol} / \mathrm{l}$ sodium citrate buffer $(\mathrm{pH} 6.0)$ in $90^{\circ} \mathrm{C}$ solution of $0,001 \mathrm{~mol} / \mathrm{l}$ EDTA for $20 \mathrm{~min}$. Endogenous peroxidase activity was quenched with $3 \%$ hydrogen peroxide in distilled water. Slides were treated with $1 \%$ bovine serum albumin (BSA) (Santa Cruz Biotechnology, Dallas, TX, USA), and 5\% normal goat serum in PBS containing $0.05 \%$ Triton (Merck, Kenilworth, NJ, USA) and incubated in a closed humid chamber overnight at $4^{\circ} \mathrm{C}$ with the following antibodies: GFAP (1:200 dilution, Abcam, ab7260, Cambridge, UK); Olig-2 (1:50; Abcam, ab42453); EMA (1:100; LSBio, LS $\square$ C77445, Huissen, Netherlands) and MIB1 (1:50, LSBio, LS $\square$ C99610). Staining was detected using the EnVision+SystemHRP Labeled Polymer Anti-Rabbit or Anti-Mouse for 1 hour at room temperature and then the Chromogen DAB/substrate reagent (Dako, Glostrup, Denmark). Slides were counterstained with hematoxylin (Merck), dehydrated and mounted. Quantitative analyses were performed on three to five independent fields by counting the number of cells using the $40 \times$ objective of a Leica DM-LB microscope. Histological samples were analyzed by independent and experienced neuropathologists.

Whole-exome sequencing (WES) and array CGH analysis. For WES, DNA of the tumor specimen was isolated from a portion of FFPE specimen using the NucleoSpin DNA FFPE XS kit (Macherey-Nagel, Duren, Germany); in parallel, peripheral blood DNA of the patient was isolated using QIAmp Blood DNA Mini kit (Qiagen, Hilden, Germany). Genomic DNA samples were then visualized with a $1 \%$ agarose gel electrophoresis and quantified using Qubit DNA HS kit (Invitrogen, Carlsbad, CA, USA) and Nanodrop 2000 (ThermoFisher Scientific, Waltham, MA, USA) instruments. DNAs were then gently sonicated to achieve an average fragment size of 250 base pairs, size selected and barcoded. Multiplexed pools were hybridized with biotinylated baits (Truseq Exome library Prep kit, Illumina, San Diego, CA, USA) designed to capture exonic sequences. The captures were sequenced on the NextSeq500 (Illumina, San Diego, CA, USA) and mutation analysis was performed by MuTect2 (GATK version 4.beta.4-SNAPSHOT built at 13-45-2017) according to Best practices di GATK. ArrayCGH analyses were performed by using the $180 \mathrm{~K}$ chip (Agilent Technologies, Santa Clara, CA, USA) according to the manufacturer's protocol. In brief, both test and reference DNAs were labelled using the SureTag Labeling Kit (Agilent Technologies). After overnight hybridization, images of the arrays were acquired with the Agilent scanner at resolution of $3 \mu \mathrm{m}$. Data analysis and interpretation was performed by means of the Feature Extraction v.10 software (Agilent Technologies) and the Agilent Genomic Workbench Standard Edition v.7.0. Genomic positions were referred to GRCh37. Two distinct array experiments were performed in order to better characterize the genomic profile of the tumor. The first array test was done by hybridizing cancer DNA $v s$. blood DNA, while the second experiment by comparing the patient's blood DNA and a sex-matched reference DNA extracted from the peripheral blood of a healthy well characterized individual. Combining the results from these two experiments, CNVs acquired by the cancer DNA and those absent in the patient's constitutional genome were highlighted.

Real-time PCR (allelic discrimination) assay. The BRAFV600E mutation was determined by an allelic discrimination Real-time PCR based approach using specific Taqman validated primers and probes (Assay ID BRAF_476_mu, ThermoFisher Scientific). VIClabeled probe was specific for the $w t$ sequence, whereas FAM labeled one was complementary to the mutant allele. Sample $\Delta \mathrm{C}_{\mathrm{t}}$ values were calculated as the difference between the mutation assay $\mathrm{C}_{\mathrm{t}}$ (FAM-probe) and the $w t$ assay $\mathrm{C}_{\mathrm{t}}$ (VIC-probe) from the same sample. Reactions were performed using tumor $1 \mathrm{ng}$ of DNA as a template on a Real-Time PCR StepOne Detection System (Applied Biosystems, Foster City, CA, USA) under the following cycling conditions: denaturation at $94^{\circ} \mathrm{C}$ for $3 \mathrm{~min}$, and 45 cycles of $95^{\circ} \mathrm{C}$ for $15 \mathrm{sec}$ and $60^{\circ} \mathrm{C}$ for $1 \mathrm{~min}$ (with single fluorescence acquisition). The amplification curves were analyzed by using StepOne Software v2.3 (Applied Biosystems).

BRAFV600E detection using Digital Polymerase Chain Reaction $(d P C R)$. The TaqMan BRAF SNP Genotyping assay was used for dPCR detection. Each $15 \mu \mathrm{l}$ dPCR reaction contained $0.375 \mu \mathrm{l}$ 
BRAF assay, 7.5 $\mu$ l QuantStudio 3D Digital PCR Master Mix 2X (ThermoFisher Scientific), $6.125 \mu \mathrm{l}$ nuclease-free water (ThermoFisher Scientific), and $1 \mu \mathrm{l}$ DNA. The dPCR reactions were then loaded onto a QuantStudio 3D Digital PCR Chip v2 (ThermoFisher Scientific). The chips were performed using QuantStudio 3D Digital PCR System (ThermoFisher Scientific) according to the manufacturer's protocols. The dPCR cycling was performed as follows: Initial denaturation at $96^{\circ} \mathrm{C}$ for $10 \mathrm{~min}$, followed by 40 cycles of denaturation at $95^{\circ} \mathrm{C}$ for $5 \mathrm{sec}$, annealing at $60^{\circ} \mathrm{C}$ for $30 \mathrm{sec}$ and elongation at $72^{\circ} \mathrm{C}$ for $1 \mathrm{~min}$. The levels of $w t$ and mutated DNA were determined using QuantStudio 3D Analysis Suite Software (ThermoFisher Scientific) by analyzing the numbers and proportions of positive/negative droplets.

Genes-fusions detection. To detect tumor genes-fusion events from a low input RNA content of the tumor FFPE biopsy specimen, a QuantSeq 3' mRNA-Seq Service for Illumina NextSeq 500 was performed by Lexogen (Wien, Austria) in triplicates. Sequencing was performed as $72 \mathrm{bp}$ single-end reads and then raw sequences (about 47 million reads per sample) were aligned to hg38 reference genome and transcriptome within the following gene-fusion detection methods: JAFFA (1.09v) (18), TopHat-Fusion (2.1.0v) (19) and FusionMap (10.0.1.29v) (20) using standard settings. Each read was evaluated after read mapping using 'split reads' method (TopHatFusion, FusionMap) or de novo assembled into contigs and aligned to the transcriptome (JAFFA) for identifying potential fusion events. Fusion results were filtered according to the following criteria: i) span reads were $>3$ reads or span reads equal to 1 read but the candidate event was present in half of the analyzed samples; ii) gene fusions involving ribosomal proteins, small nuclear ribosomal proteins or pseudogenes were excluded; iii) presence of supporting information in the Miltelman (21), COSMIC (22) and ChimericDB (23) mutational databases. Primers for RPS6KBP1:VMP1, ARFGEF2:SULF2 and XRN2:AHDC1 predicted chimeric transcripts as well as pilocytic astrocytoma common genes fusions $B R A F: K I A A 1549$, are reported in Table I. For genes-fusion analysis, total RNA was isolated from a small portion of FFPE tumor slices using NucleoSpin total RNA FFPE XS kit (Macherey-Nagel, Duren, Germany), quantified using Qubit RNA Hs assay (Invitrogen), retrotranscribed to cDNA and amplified with Power SYBR Green RNAto-Ct 1-Step kit (Applied Biosystems). Real-time PCR were performed with Step-One PCR Instrument (Applied Biosystems) using $1 \mathrm{ng}$ of cDNA, with the following thermal profile: incubation of $50^{\circ} \mathrm{C}$ for $2 \mathrm{~min}, 95^{\circ} \mathrm{C}$ for $2 \mathrm{~min}$, followed by 45 cycles of denaturation at $95^{\circ} \mathrm{C}$ for $15 \mathrm{sec}$, annealing at $57^{\circ} \mathrm{C}$ for $20 \mathrm{sec}$ and elongation at $72^{\circ} \mathrm{C}$ for $1 \mathrm{~min}$. Melting curve analysis from $57-94^{\circ} \mathrm{C}$, collecting data every centigrade degree was performed.

Urine exosomes isolation and characterization. Exosomes were isolated from freshly patient's urine samples as follows. Urine volumes of approximately $150 \mathrm{ml}$ were primarily concentrated and reduced to $15 \mathrm{ml}$ volumes using TFF Easy filter cartridges (Lonza, Basel, Switzerland) as recommended. Next, exosomes were collected using Total Exosome Isolation Reagent (from urine) (ThermoFisher Scientific) and re-suspended into $500 \mu \mathrm{l}$ of D-PBS. For gene expression analysis, total RNA was isolated from exosomes using Total Exosome RNA Isolation kit (Invitrogen), quantified using Qubit RNA Hs assay (Invitrogen), retro-transcribed to cDNA and amplified with Power SYBR Green RNA-to-Ct 1-Step kit (Applied Biosystems). Real-time PCR were performed with Step-One PCR
Table I. Gene-fusion primers.

\begin{tabular}{|c|c|c|}
\hline Gene fusions & Sequence $5^{\prime}->3^{\prime}$ & bp \\
\hline$R P S 6 K B P 1: V M P 1$ & $\begin{array}{l}\text { AAATATTTGCCATGAAGGTGCTT } \\
\text { ACGACCAACTTTTCAAACATCCA }\end{array}$ & 75 \\
\hline ARFGEF2:SULF2 & $\begin{array}{l}\text { AGCCATACAGAAGAAGCAGC } \\
\text { CCGGGTCTTGTTCATCACCT }\end{array}$ & 76 \\
\hline$X R N 2: A H D C 1$ & $\begin{array}{l}\text { AGTTGGTGAAGTTGAGGATAGCA } \\
\text { CTCTCGCTCTCTCTCTCTCT }\end{array}$ & 100 \\
\hline $\begin{array}{l}\text { BRAF:KIAA1549 } \\
\text { exons 9:16 }\end{array}$ & $\begin{array}{l}\text { CCCTGCAGTGACTTGATTAGAGA } \\
\text { AACTGCTGAGGTGTAGGTGC }\end{array}$ & 340 \\
\hline $\begin{array}{l}\text { BRAF:KIAA1549 } \\
\text { exons 9:15 }\end{array}$ & $\begin{array}{l}\text { TCGGATGCCCAGACTTGATT } \\
\text { AACTGCTGAGGTGTAGGTGC }\end{array}$ & 354 \\
\hline $\begin{array}{l}\text { BRAF:KIAA1549 } \\
\text { exons 9:11 }\end{array}$ & $\begin{array}{l}\text { CCTGCAGTAAAACACTTGGTAGAC } \\
\text { AACTGCTGAGGTGTAGGTGC }\end{array}$ & 169 \\
\hline
\end{tabular}

Instrument (Applied Biosystems) using $1 \mathrm{ng}$ of exosome cDNA, to the following thermal profile: $94^{\circ} \mathrm{C}$ for $3 \mathrm{~min}$, followed by 40 cycles of denaturation at $94^{\circ} \mathrm{C}$ for $10 \mathrm{sec}$, annealing at $60^{\circ} \mathrm{C}$ for $30 \mathrm{sec}$ and elongation at $72^{\circ} \mathrm{C}$ for $1 \mathrm{~min}$. Validated QuantiT Primer Assaysspecific primers (Qiagen) Hs_SYNU2_1_SG, Hs_ZDHHC14_1_SG, Hs_SNX9_1_SG and Hs_TULP4_1_SG were used as recommended for SYNU2, ZDHHC14, SNX9 and TULP4 amplifications, respectively. The qNano Gold instrument (Izon Science, Christchurch, New Zeeland) was employed to measure the size distribution and concentration of the isolated urine exosomes using the Tunable Resistive Pulse Sensing (TRPS) principle (24). Briefly, $35 \mu$ of purified exosomes were analyzed with qNANO Gold instrument using a NP200 Nanopore (Izon Science) and applying $46 \mathrm{~nm}$ stretch, $0.1 \mathrm{~V}$ and $10 \mathrm{mPa}$ parametric conditions.

\section{Results}

Histological characterization. The resected tumor specimen was subjected to microscopic analysis. As documented in Figure 1, the lesion consisted of elongated bipolar cells with low to moderate cellularity, rare Rosenthal fibers on fibrillary and microcystic areas. The tumor cells exhibited typical pilocytic astrocytoma features with rare mitotic figures. Immunohistochemistry revealed that tumor cells were positive for GFAP and Olig-2 proteins while negative for EMA expression. Proliferation index was evaluated as 1$2 \%$ by MIB 1 expression (Figure 2).

Detection of BRAFV600E mutation. Genomic DNA from a portion of the FFPE specimen was extracted as described, analysed in its integrity and quantified by Nanodrop (380 ng/ $\mu \mathrm{l}$; $\left.\mathrm{OD}_{260 / 280}=1.9\right)$ and Qubit (300 ng/ $\left.\mu \mathrm{l}\right)$. Following gel electrophoresis, isolated DNA showed the expected fragmentation pattern (Figure 3A). A specific TaqMan PCR allelic assay was employed for BRAFV600E genotyping. Realtime PCR amplifications highlighted the presence of the $w t$ allele (VIC) and did not reveal the mutated (FAM) one (Figure 3B); similarly, digital PCR detection on 4563 droplets showed 

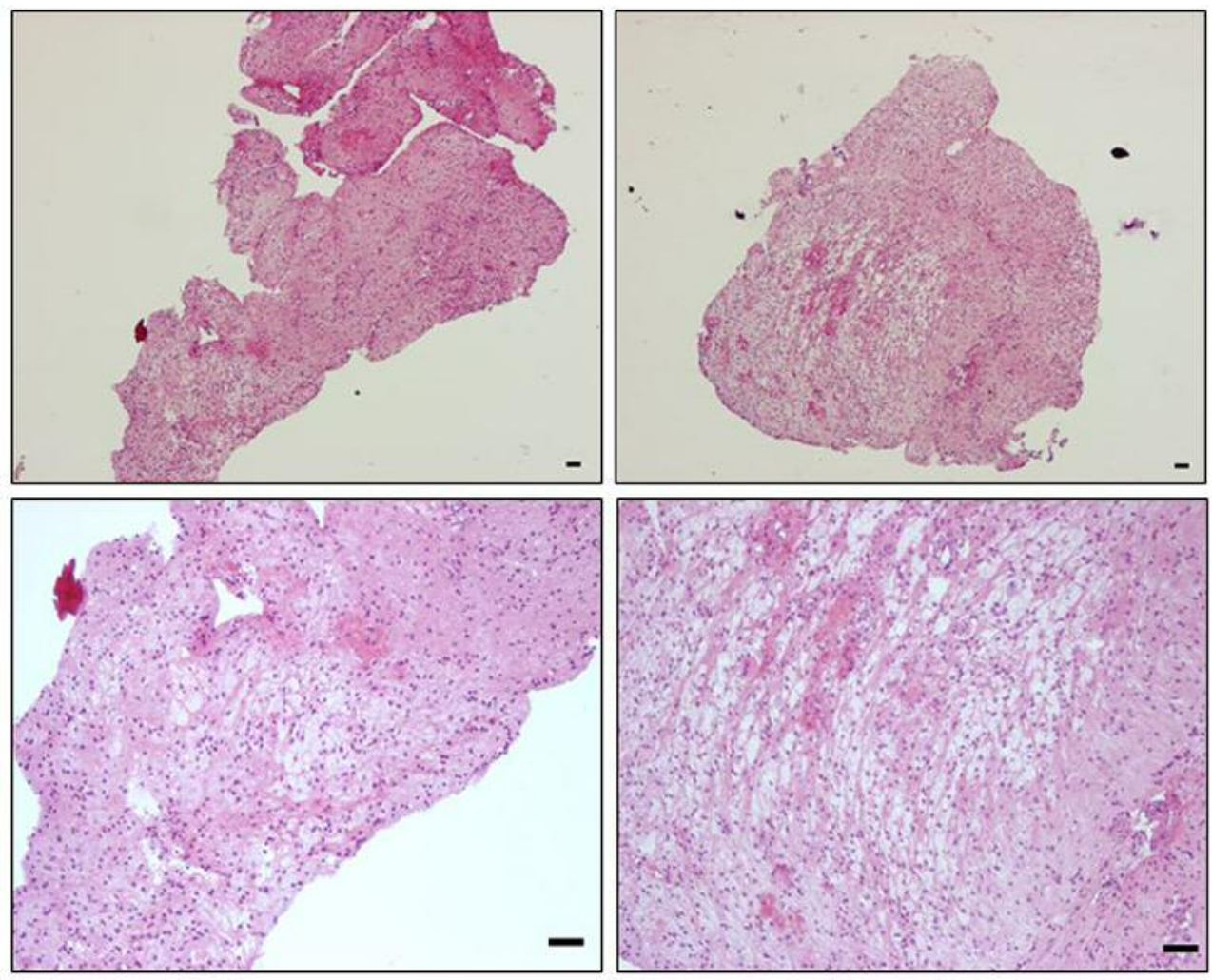

Figure 1. Tumor specimen histology. Hematoxylin\&Eosin staining of FFPE tumor slides showing classical pilocytic astrocytoma features as astrocytic hair-like polar protrusions and Rosenthal fibers. Scale bar $=50 \mu \mathrm{m}$.

in tumor DNA $0 \%$ positive amplicons for FAM mutated dye, while peripheral blood DNA displayed $64.65 \%$ positive signals for VIC $w t$ dye.

Whole-exome sequencing (WES) and urine exosomes isolation. Genomic DNA isolated from FFPE specimen was subjected to WES analysis. To identify somatic and germline mutations, tumor DNA was compared to the genomic one extracted from peripheral lymphocytes of the patient. As a primary output quality, tumor DNA sequencing showed a $277 \mathrm{X}$ coverage, compared to lymphocyte sample (97X). Most significant single nucleotide (SNV) and insertions/deletions (indels) variants predicted by Mutect 2 software are reported in Table II.

As highlighted, five genes (i.e. DEFB119, MUC5B, NUDT1, $\angle T B P 3$ and $C P S F 3 L$ ) displayed unique somatic SNV within the tumor sample. However, none of the top-listed gene variants was previously described in glioma/astrocytoma/glioblastoma mutation studies; furthermore, these hits were also absent within oncogenes and tumor suppressors databases (i.e. ongene. bioinfo-minzhao.org/; bioinfo.uth.edu/TSGene/). In addition, the identified variations were absent from the Cosmic Catalogue of Somatic Variations (cancer.sanger.ac.uk/cosmic, searching for "Astrocytoma WHO Grade I" and "spinal cord" terms) (data not shown). As illustrated in Table II, the most relevant indel variation was an in-frame insertion of the trinucleotide GCC at Chr7: 96,635,420 position, according to human hg19 reference, as illustrated using IGV sequence visualizer (Figure 4A). As schematized in Figure 4B, this variation affected SNP rs559903070, resulting in the insertion of an extra Proline residue at position 45 of the $D L X 6$ coding sequence or producing an intron variant within DLX6-AS1 lncRNA on the opposite DNA strand. DLX6 multiple protein alignment revealed that the amino-acid insertion was only detected in chimpanzee protein sequence (Figure 5A); however, Mutagene analysis (www.ncbi.nlm.nih.gov/research/mutagene/gene) revealed that this insertion was not scored in cancer databases, where only a potential driver mutation within DLX6 was identified at Serine 60 residue (Figure 5B). To further analyze cancer OMICS data, the UALCAN tool (25) was employed, matching DLX6 expression with different WHO grades of astrocytic tumor databases (specifically, TCGA and MET500). As a result, plots depicting gene expression indicated that normal samples showed the highest DLX6 expression levels compared with primary glioma tumors. A slight but not significant increase in survival rate $(p=0.66)$ was scored compared DLX6 high to medium/low expression in Kaplan- 

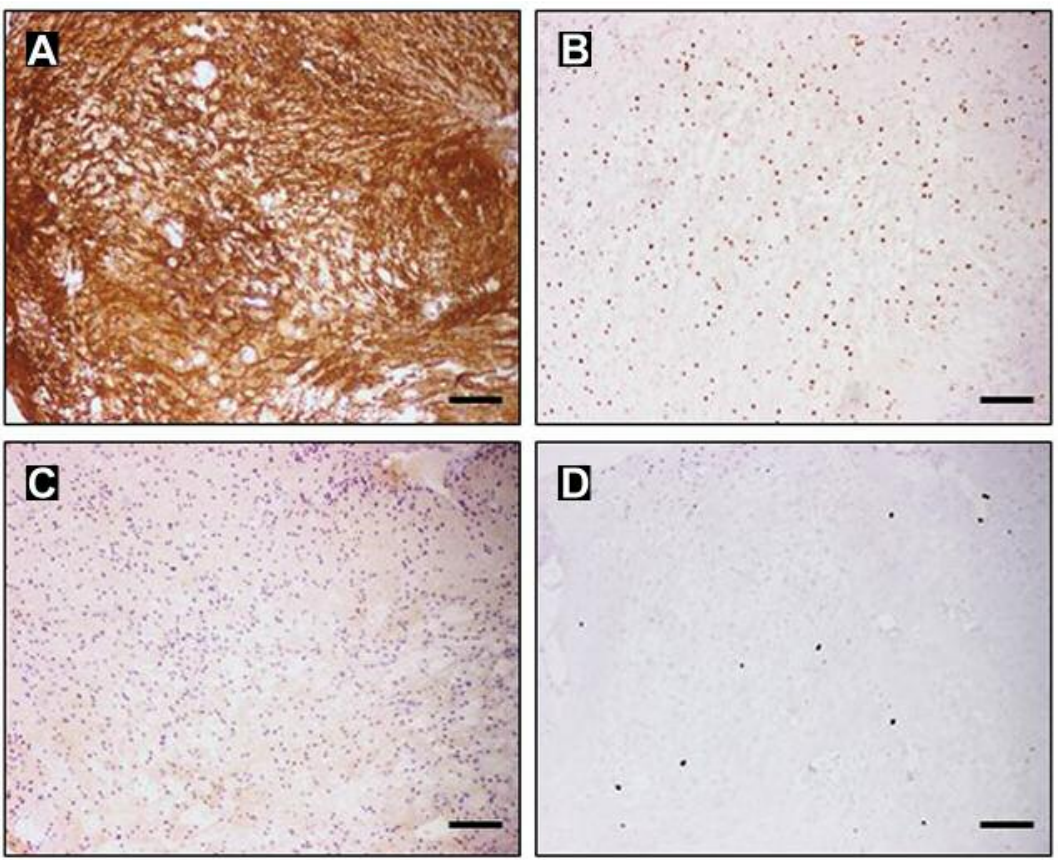

Figure 2. Immunohistochemistry analysis of the tumor specimen. (A) GFAP, (B) Olig-2, (C) EMA and (D) MIB1 protein expression. Scale bars= $50 \mu \mathrm{m}$.

A

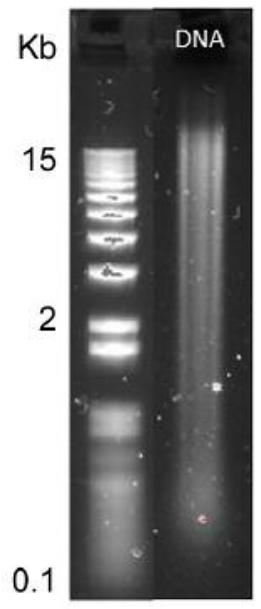

B

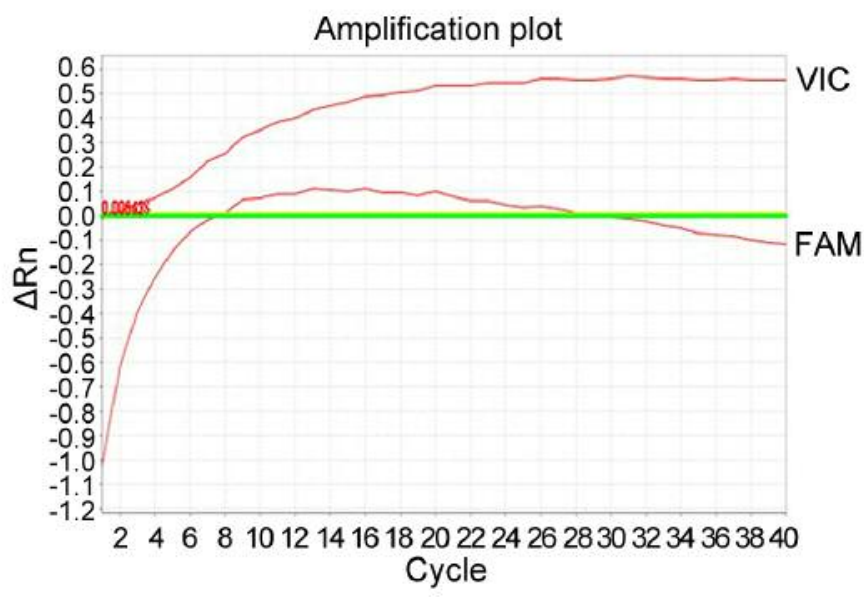

Figure 3. Tumor DNA analysis and BRAFV600E genotyping. (A) Gel electrophoresis analysis of tumor FFPE isolated DNA. (B) Allelic-real time PCR analysis of BRAFV600E genotype using Taqman VIC (wt) and FAM (mutated) dyes. PCR cycles (X axis) and fluorescence detection in arbitrarily units ( $Y$ axis) are reported.

Meier curves (Figure 6). On the other hand, the predicted Lnc $D L X 6$-AS1 mutation mapped within the intron 1 sequence and might affect the acceptor splicing site ctgcgagtgcgg (according to SplicePort: An Interactive Splice Site Analysis Tool, http://spliceport.cbcb.umd.edu/; Cutoff=0.643; Score=0.888). As recently documented, the expression of lnc DLX6-AS1 was related to important tumor features (26). Remarkably, DLX6AS1 mRNA expression was detected within exosome vesicles, according to the repository exoRBase database (exorbase.org) of circular RNA (circRNA), long non-coding RNA (lncRNA) and messenger RNA (mRNA) derived from RNA-seq data analyses of human liquid biopsies derived exosomes. 
Table II. Whole-exome sequencing (WES) nucleotide variations.

\begin{tabular}{|c|c|c|c|c|c|c|c|c|c|}
\hline \multirow[t]{2}{*}{ Chr } & \multirow[t]{2}{*}{ Position } & \multirow[t]{2}{*}{ ID } & \multirow[t]{2}{*}{ Ref } & \multirow[t]{2}{*}{ Var } & \multirow[t]{2}{*}{ Gene } & \multirow[t]{2}{*}{ AA Var } & \multicolumn{3}{|c|}{ Reads } \\
\hline & & & & & & & Ref & Var & $\%$ \\
\hline 7 & $96,635,420$ & rs559903070 & $A$ & AGCC & $D L X 6-A S 1$ & $\mathrm{P}$ & 22 & 67 & 44.9 \\
\hline 20 & $45,194,992$ & & $\mathrm{~T}$ & G & $S L C_{13} A_{3}$ & NC & 37 & 102 & 41.2 \\
\hline 20 & $29,965,087$ & 7 rs766006707 & 7C & $\mathrm{T}$ & DEFB119 & NC & 33 & 103 & 34.3 \\
\hline 11 & $1,258,241$ & rs79773885 & A & G & $M U C_{5} B$ & NC & 13 & 44 & 30.2 \\
\hline 19 & $45,864,923$ & & $\mathrm{~T}$ & G & $E R C C 2$ & $G \rightarrow G$ & 41 & 161 & 29.3 \\
\hline 19 & $36,211,740$ & & A & C & $K M T 2 B$ & $P \rightarrow P$ & 21 & 60 & 27.0 \\
\hline 11 & $1,258,240$ & rs77287508 & C & $\mathrm{T}$ & $M U C_{5} B$ & $A \rightarrow V$ & 13 & 42 & 26.8 \\
\hline 20 & $1,895,990$ & & G & $\mathrm{T}$ & SIRPA & $\mathrm{NC}$ & 114 & 368 & 25.8 \\
\hline$x$ & $51,075,841$ & rs2625875 & A & G & NUDT1 & $T->T$ & 26 & 111 & 25.5 \\
\hline 1 & $19,511,692$ & & $\mathrm{~T}$ & G & UBR4 & $\mathrm{NC}$ & 37 & 111 & 24.4 \\
\hline 17 & $45,221,346$ & & G & GCCCTTGTCG & $C D C 27$ & NC & 12 & 75 & 23.5 \\
\hline 17 & $45,221,348$ & & A & ACCTIT & $C D C_{27}$ & NC & 12 & 44 & 22.1 \\
\hline 8 & $144,812,769$ & & T & G & FAM $83 \mathrm{H}$ & NC & 16 & 54 & 21.3 \\
\hline 3 & $63,542,375$ & & C & A & SYNPR & $F->L$ & 46 & 99 & 20.2 \\
\hline 3 & $183,750,645$ & & A & C & HTR3D & NC & 49 & 175 & 19.9 \\
\hline 5 & $121,187,876$ & & A & C & FTMT & $\mathrm{H}->\mathrm{P}$ & 37 & 97 & 19.7 \\
\hline 7 & $27,934,921$ & & $\mathrm{~T}$ & G & $J A Z F_{1}$ & NC & 34 & 143 & 18.7 \\
\hline 16 & $57,693,590$ & & $\mathrm{~T}$ & G & GPR56 & NC & 30 & 125 & 17.4 \\
\hline 9 & $139,902,792$ & & A & C & $A B C A 2$ & NC & 65 & 208 & 16.3 \\
\hline 2 & $9,533,723$ & & A & C & $A S A P 2$ & NC & 23 & 62 & 16.0 \\
\hline 19 & $55,297,784$ & rs367758983 & C & $T$ & $K I R 2 D L 4 / K$ & NC & 43 & 169 & 15.8 \\
\hline 11 & $65,321,022$ & & $\mathrm{~T}$ & G & $\angle T B P_{3}$ & NC & 26 & 73 & 15.7 \\
\hline 1 & $1,254,305$ & & A & C & $\mathrm{CPSF}_{3} \mathrm{~L}$ & NC & 23 & 63 & 15.1 \\
\hline 12 & $121,432,238$ & & $\mathrm{~T}$ & G & $H N F 1 A$ & NC & 29 & 102 & 14.9 \\
\hline 7 & $36,552,790$ & $r s 200966652$ & G & T & $A O A H$ & NC & 105 & 334 & 14.0 \\
\hline 6 & $144,263,065$ & & $\mathrm{~T}$ & G & PLAGL1 & NC & 45 & 148 & 13.8 \\
\hline$x$ & $153,278,829$ & rs1059703 & G & A & IRAK1 & NC & 20 & 38 & 13.5 \\
\hline 2 & $27,590,854$ & & T & G & $E_{I} F_{2} B_{4}$ & NC & 97 & 345 & 13.3 \\
\hline
\end{tabular}

Main relevant nucleotide variations and chromosome ( $\mathrm{Chr}$ ) positions are referred to hg19 human reference sequence. Synonymous and nonsynonymous amino acidic variations (AA Var) are highlighted. Number and percentages of reference (Ref) or mutated (Var) are reported. Nucleotide variations scored only in tumor DNA exome sequence are indicated in grey. Reference (Ref) and mutated (var) reads are reported.

Based on these premises, exosomes of the patient were collected from $150 \mathrm{ml}$ of fresh urine, concentrated and subjected to isolation procedure as described in the Materials and Methods Section. Size and microvescicles concentration of purified exosomes were determined using unable Resistive Pulse Sensing (TRPS) principle in combination with qNANO Gold technology. As illustrated in Figure 7, typically from a concentrated urine sample, $2 \times 10^{11}$ total exosomes, ranging from 70-180 nm were recovered. Next, DLX6-AS1 expression was investigated by Real-time PCR in RNA isolated form urine exosomes of the patient during a one-year follow up, showing however no significant expression variations along this period (data not shown).

Array $\mathrm{CGH}$ analysis. In order to highlight chromosomal differences in the tumor specimen, genomic DNAs of tumor samples and peripheral lymphocyte controls were subjected to array $\mathrm{CGH}$ analysis. The results, reported in Figure 8, pointed for a 6q25.3 copy number loss from 157950057 to 158967394 bp (GRCh37 nucleotide coordinates) with an average $\log _{2}$ ratio of -0.67 , indicated that the $1,01 \mathrm{Mb}$ deletion was present in about $75 \%$ of the cells of the tumor specimen. No additional copy number changes were scored. To confirm that the deletion arose from tumor cells a second array-CGH experiment, in which the DNA extracted from the peripheral blood was hybridized to a different sexmatched reference DNA, was performed. The second experiment did not show any CNV at 6q25.3 confirming that the deletion was present only in cancer cells (data not shown). The deletion region encompassed $\mathrm{ZDHHC14}$, SNX9, SERAC1, TULP4, GTF2H5, DYNLT1 and SYTL3 genes, suggesting that their expression could be influenced 
A

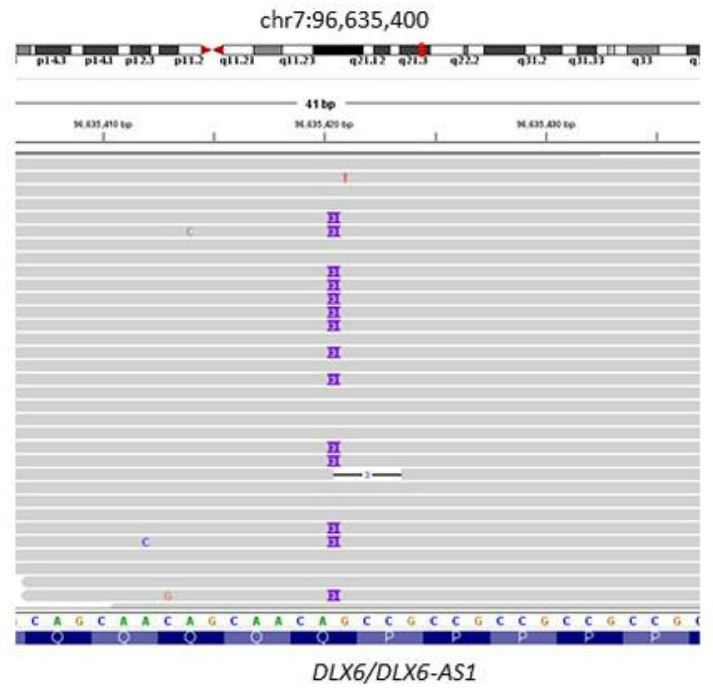

B

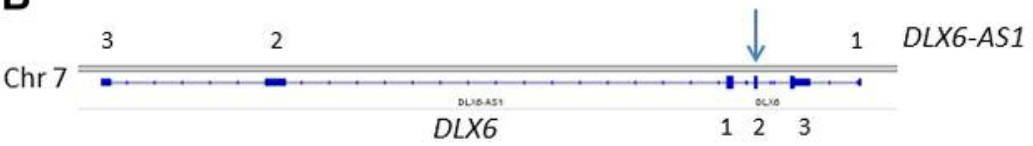

Figure 4. Exome visualization and genomic mapping of DLX6/DLX6-AS1 variation. (A) The GCC insertion at chr7:96,635,420 (referred to hg19) is visualized by the IGV tool in WES reads of the tumor specimen DNA resulting in an inframe Proline insertion within the DLX6 coding region or in an intronic insertion in the Lnc DLX6-AS1 gene. (B) Chromosomal organization highlighting exon numbers and architecture of DLX6 and DLX6AS1 genes. The WES identified variation is indicated with the blue arrow.

by the genomic imbalance. The expression of four of these genes (i.e. ZDHHC14, SNX9, TULP4 and SYTL3) were periodically evaluated form freshly isolated urine-derived exosomes of the patient, showing, in the last one year survey, no significant variation in their expression levels (data not shown).

Gene fusion detection. To investigate potential gene fusions in the tumor tissue specimen of the patient, RNA-seq and the main gene-fusion predicting tools were employed. JAFFA, TopHat-Fusion and FusionMap algorithms produced different results and no common predicted fusions were detected. This issue could be due to the low and deteriorated input RNA that has been sequenced, and, as a consequence, only a small fraction of the raw reads aligned to the reference (i.e. about $16 \%$ of the sample raw reads). Applying the filtering criteria (see Materials and Methods section) on the obtained results from three analysis pipelines, FusionMap predictions were excluded since the only four identified gene fusions involved 'blacklisted' genes, that are ribosomal genes or pseudogenes (data not shown). For a validation analysis, RPS6KBP1:VMP1, $A R F G E F 2: S U L F 2$ and XRN2:AHDC1 candidate chimeric transcripts that matched the selection filters were selected (Table III). Genes-fusion specific primers were, therefore, designed for the above mentioned chimeric potential transcripts and assayed in Real-time PCR analysis on cDNA derived from tumor sample. However, no specific amplification signals for all the predicted fusions were obtained (data not shown). Noticeable, neither JAFFA nor Tophat algorithms did predict for RNA data the pilocytic astrocytoma frequent fusion event between $B R A F$ and KIAA1549 genes. To verify the accuracy in absence of prediction, specific primers for the main exons involved in $B R A F$ and KIAA1549 fusions were designed (namely, BRAF exon 9-KIAA1549 exon 16; BRAF exon 11-KIAA1549 exon 16 and BRAF exon 9-KIAA1549 exon 15). In order to define a positive control harboring the three investigated fusion events, considering that oncogenic BRAF alterations including BRAF-KIAA1549 fusions were detected in different brain tumors (17), a pool of cDNA derived from 50 biopsy specimens of different astrocytoma malignancy was created and tested for the BRAF-KIAA1549 fusion events. In astrocytoma samples, only BRAF exon 11KIAA1549 exon 16 fusion gave amplification curves and products. This amplicon was Sanger sequenced confirming the $B R A F: K I A A 1549$ fusion event. Next, cDNA of the tumor specimen was amplified using the three different primers combinations, giving no amplification signals for the investigated BRAF:KIAA1549 fusions (Figure 9). 
A

CLUSTAL 2.1 multiple sequence alignment

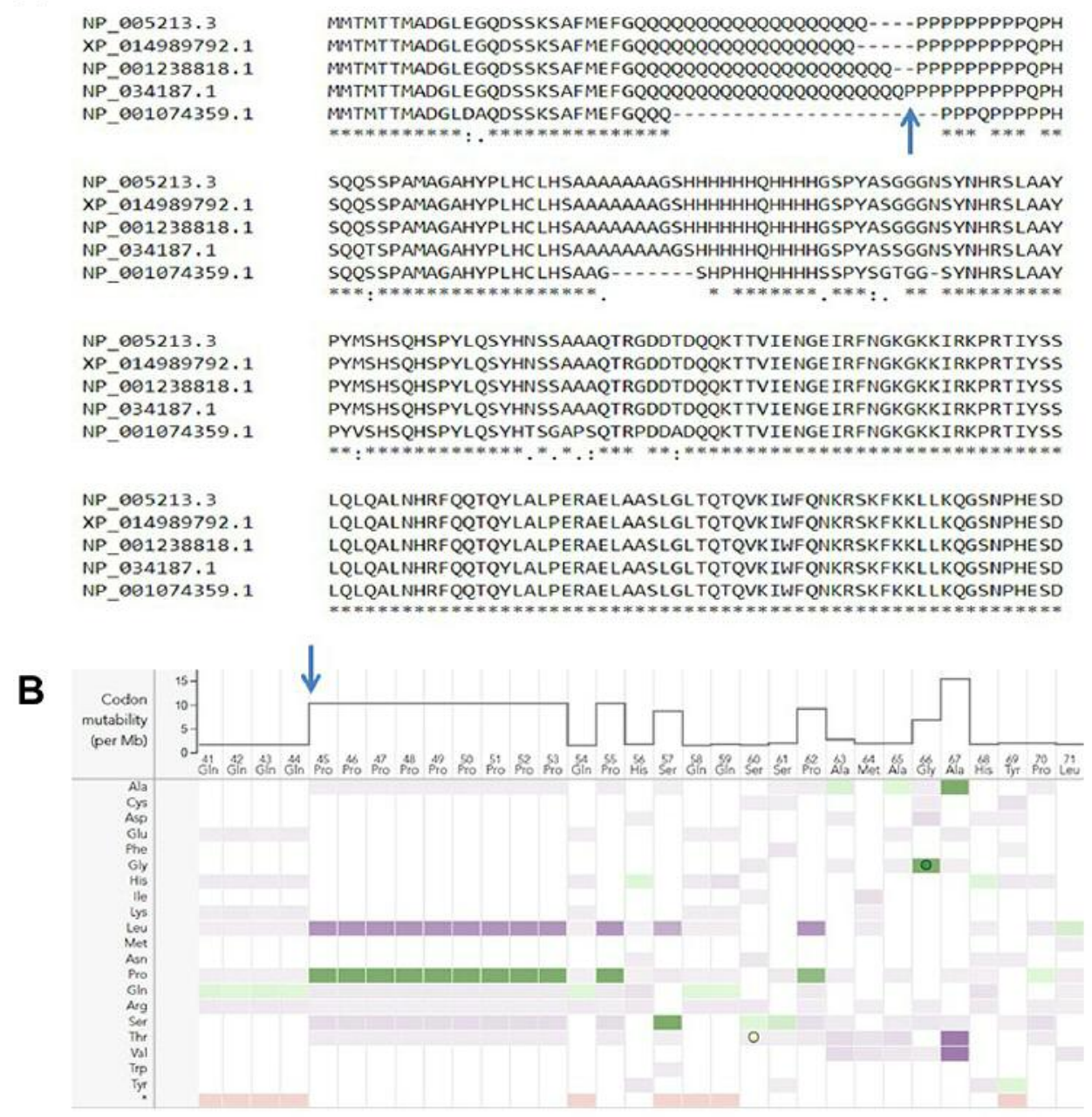

Figure 5. DLX6 protein sequences containing the WES identified variation. (A) Clustal W multiple DLX6 proteins alignment (accession numbers are referred to human, mouse, chicken, chimpanzee and macaco sequences, respectively). Variation is indicated with a blue arrow. (B) Mutagene analysis in Pan-cancer databases of the chr7:96,635,420 (referred to hg19) WES identified mutation. A unique Serine 60 potential driver mutation was scored (yellow circled). Bar colors indicated missense (violet), silent (green) and Nonsense and loss of start/stop codon mutations (brown).
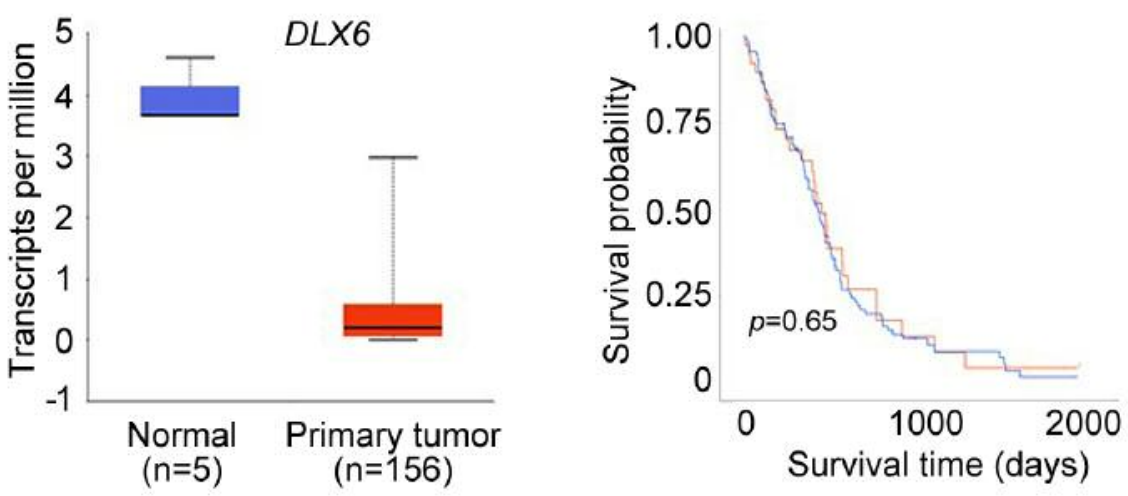

Figure 6. DLX6 expression in tumor and survival prediction. (Left) DLX6 expression plots in normal ( $n=5)$ and primary glioma tumors $(n=156)$ using the UALCAN OMICS tool comparing normal to tumor glioma databases (specifically, TCGA and MET500). (Right) Kaplan-Meier survival predicting curves related to high ( red, $n=39$ ) and low-to-medium DLX6 expression (blue, $n=113$ ). 


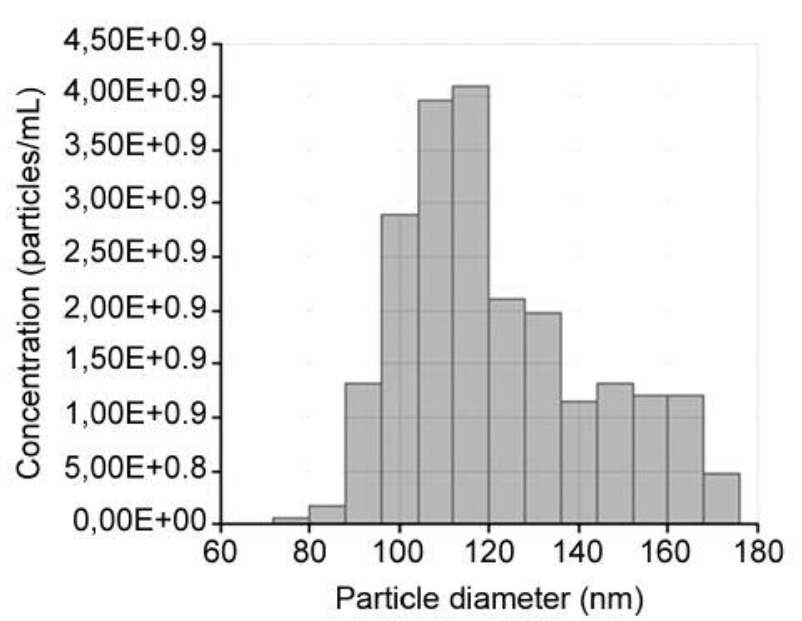

Figure 7. Peripheral exosomes size distribution and quantification. Exosomes were isolated from fresh urine samples of the patient and analyzed by means of TRPS technology. Size and concentration values were obtained using TKP200 polysterine beads (Izon Science) references.

\section{Discussion}

Spinal cord tumors are often histologically similar to the intracranial counterparts, but displaying genetically unique signatures. Therefore, for these cancers, a precise understanding of molecular and genetic determinants may better define the tumor classification, identify cells of origin leading to a more effective therapeutic strategy. In addition, genetic alteration studies may also serve to provide novel surrogate markers for evaluating clinical outcomes and better monitor the risk assessment for cancer recurrence. Although many studies have investigated the genetics of intracranial glial tumors, fewer studies have clearly identify the genetic determinants in spinal cord astrocytomas.

In one of the most detailed contributions, Shankar and collaborators (14) performed a genetic study on 10 spinal cord astrocytoma specimens through exome sequencing reporting that the most recurrent findings were $B R A F$ KIAA1549 translocation and BRAF copy number gain. Additionally, non-synonymous mutations in NF2, NTRK1, NTRK3, PDGFRA and TP53 genes were scored. Notably, in the described study, no specimen in the cohort displayed the BRAFV600E mutation. A very recent survey of the literature data reported that the main genetic variations associated with spinal cord astrocytomas involved BRAF-KIAA1549 fusions in about $32 \%$ of cases, and TP53 mutations in $60-67 \%$ of WHO grades III-IV spinal cord astrocytomas (27). Generally, it was also established that the molecular profile of astrocytomas in children differ significantly from the adult variants and mainly contain mutations in $B R A F, H 3 F 3 A$ and $A T R X$ genes. However, to date, there is no information on the identification of specific spinal cord astrocytomas markers such $I D H 1 / 2, H 3 F 3 A$ and $F G F R 2$ related to brain glial tumors (27).

Among all the reported genes variations, in our pediatric pilocytic spinal cord examination, we failed to detect the above mentioned genetic hallmarks. Differently, unique mutations in the tumor tissue for $D E F B 119, M U C 5 B$, NUDT1, LTBP3 and CPSF3L genes were reported. DEFB119 encodes a member of the beta subfamily of defensins, antimicrobial peptides that protect tissues and organs from infection by a variety of microorganisms. Its involvement in cancer progression was not reported. $M U C 5 B$ is a member of the mucin family of proteins, which are highly glycosylated macromolecular components of mucus secretions. This family member is the major gel-forming mucin in mucus. It is a major contributor to the lubricating and viscoelastic properties of whole saliva, normal lung mucus and cervical mucus. This gene has been found to be up-regulated in some human diseases, including sinus mucosa of chronic rhinosinusitis (CRS), CRS with nasal polyposis, chronic obstructive pulmonary disease (COPD) and $H$. pylori-associated gastric disease, and it may be involved in the pathogenesis of these diseases (28). Although Liu and collaborators (29) recently reported that recurrent mutations in MUC genes, including MUT5B, were significantly associated with better survival prognosis in several cancer patients, the MUT5B rs79773885 A (Ala)>A (Ala) synonymous variant described in our study was not associated with pathogenesis. NUDT1 protein hydrolyzes oxidized purine nucleoside triphosphates, such as 8-oxodGTP, 8-oxo-dATP, 2-hydroxy-dATP, and 2-hydroxy rATP, to monophosphates, thereby preventing nucleotides misincorporation. It was reported that the overexpression of NUDT1 correlated closely with an increase in invasive depth and a decrease in survival in gastric cancer patients (30). However, the identified synonymous variation (i.e. rs2625875) was reported to not have a clinical significance. The Latent Transforming Growth Factor Beta Binding Protein 3 (LTBP3) forms a complex with transforming growth factor beta (TGF-beta) proteins and may be involved in their subcellular localization. Interestingly, the identified mutation (scored only in 14/75 tumor sample reads) lied within $L T B P 3$ intron 3, 15 nucleotides upstream of the splicing acceptor site. However, bioinformatics prediction of the possible role of the nucleotide variation in affecting splicing process did not produce significant evidences (data not reported). Importantly, it was recently reported that LTBP3 is involved in the early dissemination of primary cancer cells, namely in the intravasation step of the metastatic cascade. In fact, LTBP3 depletion diminished the angiogenesis-inducing potential of HEp-3 cells in vivo, which was restorable by exogenous delivery of LTBP3 protein. Thus, absence of functional mutation within $L T B P 3$ 

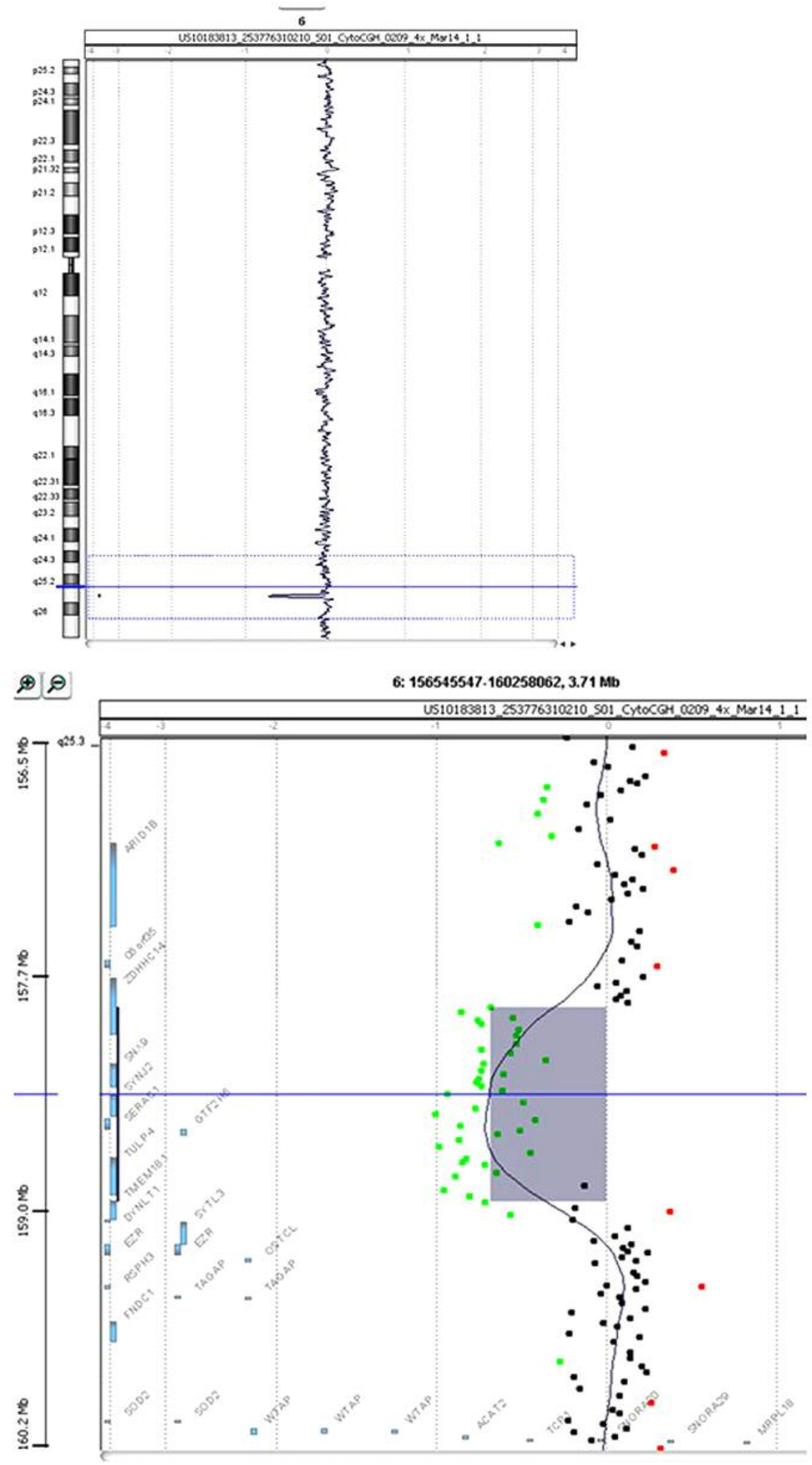

Figure 8. Array CGH analysis. Array-CGH profile of the tumor vs. peripheral blood lymphocytes of the patient showing the $6 q 25.3$ deletion in mosaic (average log2 ratio=-0.67). The top panel shows the chromosome view while the bottom panel reports the genomic profile of the 6q25.3 deleted region. 

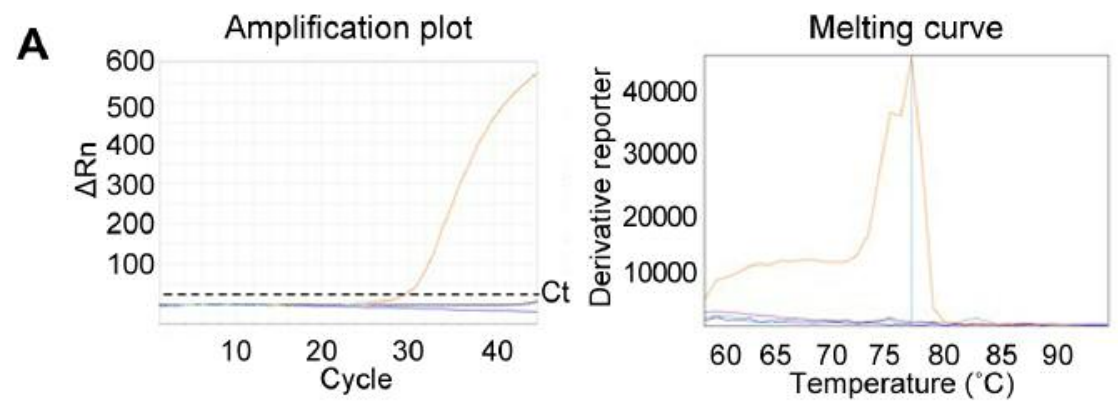

B
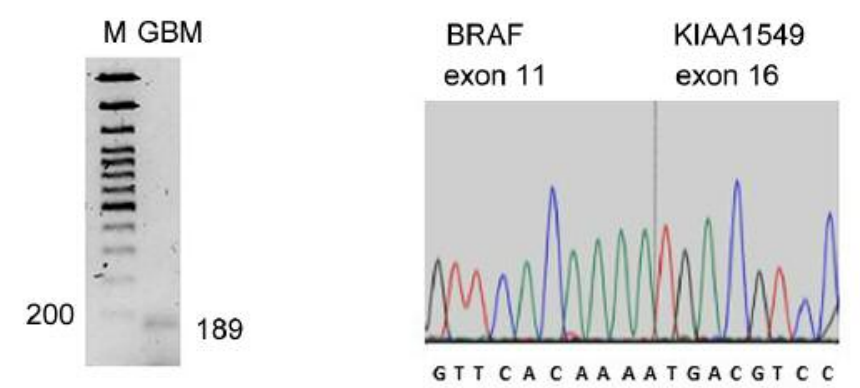

Figure 9. Real-time PCR analysis of BRAF-KIAA1549 fusions. (A) PCR amplification plots and melting curve analysis of the investigated BRAFKIAA1549 fusions (in red, BRAF exon 11-KIAA1549 exon 16 fusion transcript detected in the GBM pooled sample). The other fusions (i.e. BRAF exon 9-KIAA1549 exon 15 and BRAF exon 9-KIAA1549 exon 11) were absent in GBM pooled sample as well as in the pilocytic astrocytoma investigated specimen. (B) Gel electrophoresis and electropherogram analysis of the BRAF exon 11-KIAA1549 exon 16 fusion transcript. M and GBM indicated the $100 \mathrm{bp}$ ladder and the GBM pooled sample, respectively; molecular weights are indicated in nucleotides.

Table III. Genes' fusions prediction.

\begin{tabular}{|c|c|c|c|c|c|c|c|c|c|c|}
\hline $\begin{array}{l}\text { Fusion } \\
\text { product }\end{array}$ & $\begin{array}{l}\text { Gene left } \\
\text { fusion }\end{array}$ & $\begin{array}{l}\text { Chr left } \\
\text { gene }\end{array}$ & $\begin{array}{l}\text { Chr Coord. } \\
\text { left gene }\end{array}$ & $\begin{array}{l}\text { Gene right } \\
\text { fusion }\end{array}$ & $\begin{array}{l}\text { Chr right } \\
\text { gene }\end{array}$ & $\begin{array}{l}\text { Chr Coord. } \\
\text { right gene }\end{array}$ & $\begin{array}{c}\text { Spanning } \\
\text { reads }\end{array}$ & $\begin{array}{l}\text { Prediction } \\
\text { method }\end{array}$ & $\begin{array}{c}\text { Detected } \\
\text { samples }\end{array}$ & $\begin{array}{l}\text { Known } \\
\text { fusion }\end{array}$ \\
\hline XRN2:AHDC1 & $X R N 2$ & $\operatorname{chr} 20$ & 21334185 & $A H D C 1$ & chr1 & 27534689 & 8 & TopHat-Fusion & $1 / 3$ & Yes \\
\hline ARFGEF2:SULF2 & $A R F G E F 2$ & chr20 & 48922010 & $S U L F 2$ & $\operatorname{chr} 20$ & 47736942 & 3 & JAFFA & $1 / 3$ & Yes \\
\hline RPS6KB1:VMP1 & RPS6KB1 & $\operatorname{chr} 17$ & 59910611 & $V M P 1$ & $\operatorname{chr} 17$ & 59838295 & 1 & JAFFA & $2 / 3$ & Yes \\
\hline
\end{tabular}

Genes fusion products, chromosomes (Chr) at left and right positions, their chromosomal coordinates (Chr Coord.) are reported.

gene might confer favorable prognostic features even in the context of spinal cord pilocytic astrocytoma (31). Lastly, CPSF3L, also known as Integrator Complex Subunit 11 (INTS11) gene is a complex of at least 12 subunits and associates with the C-terminal domain of RNA polymerase II large subunit and mediates the 3-prime end processing of small nuclear RNAs U1 and U2. The identified mutation mapped within intron 4 of $C P S F 3 L$, without apparently affect splicing of other predictable transcription regulation.

RNAseq and subsequent bioinformatics analysis were employed to evaluate in the tumor biopsy specimen the presence of genes-fusions, particularly those related to the reported BRAF-KIAA1549 chimeras. This analysis failed to reveal any effective genes fusions as also verified by specific Real-time PCR amplifications. A possible indeterminacy of this result could be linked to the reduced quantity of the unique and not repeatable biological material available for RNAseq analysis and its partial degradation status.

Array CGH analysis revealed a 6q25.3 deletion within tumor specimen. This chromosomal region includes in particular the tumor suppressor zinc finger DHHC-type containing 14 (ZDHHC14). ZDHHC14 expression was significantly decreased in a panel of prostate cancer samples and cell lines and its inducible overexpression led to reduced cell viability and increased apoptosis $(32,33)$. In addition, Monoranu and collaborators (34) reported that pediatric 
anaplastic intracranial ependymomas harboring the $6 \mathrm{q} 25.3$ deletion showed significantly longer overall survival than did patients of the same group without the aberration, independent of the extent of resection. To date, our one-year survey of ZDHHC14 expression did not reveal any significant variation in $\mathrm{ZDHHC14}$ mRNA within peripheral urine-derived exosomes. Similar results were obtained evaluating the temporal expression differences in SNX9, TULP4 and SYTL3 genes. However, this analysis will be further extended over time since differences in genes expression through these liquid biopsies might indicate significant variations perturbing the homeostasis of the tumor/normal cells pointing for a possible increase of proliferation and malignancy.

The most frequently identified variant by WES analysis was SNP rs559903070. This SNP determined a DLX6 inframe deletion/insertion in one strand or a DLX6-ASI intron variant in the other DNA strand. In our study, $44.9 \%$ of tumor reads, displayed a putative inframe insertion resulting in an extra Proline residue or a tri-nucleotides insertion within an intronic sequence of DLX6-AS1 gene. The Proline insertion was localized in a Proline-rich region composed in humans by 9 residues, at $\mathrm{N}$-terminus of the mature protein, not affecting $\mathrm{Hox}$ and Abdominal $\mathrm{A}$ superfamily functional domains. While DLX6 (Distal-Less Homeobox 6) gene was not involved in cancer, differently, lnc DLX6-AS1 was very recently deeply investigated, promoting tumorigenesis in pancreatic (35), colorectal (36), ovarian (37), lung (38), gastric (39) and liver (40) cancers. These contributions pointed for a role of this lncRNA in proliferation and metastasis induction and also suggested $D L X 6-A S 1$ as a potential therapeutic target (41). Based on these evidence, we performed a molecular-based follow-up of the pediatric patient by means of liquid biopsies, consisting in urine-derived exosomes. Exosomes are nanosized extracellular vesicles with a size range of 30-150 $\mathrm{nm}$, plentiful in our body in both physiological and pathological conditions. Importantly, exosomes are important mediators of intracellular communication among tumor cells, immune cells and stromal cells. They can shuttle to different cells and body fluids bioactive molecules, such as proteins, lipids, RNA, and DNA. In recent years, tumor-associated cargo in exosomes has been a hot topic in research, especially with respect to noncoding RNAs (42). Primarily, due to large initial volumes of the biological sample, a concentration protocol was set up for exosome isolation. The quality and concentration of exosomes was assessed using the TRPS technology (18). However, according to the obtained results, no significant variations in DLX6-ASI expression was reported along one year of follow-up.

In conclusion, despite the absence of clear genetic determinants related to the investigated pediatric spinal cord pilocytic astrocytoma case, considering the above mentioned biological limitations, further research in this direction can provide much better elucidation of the genetic and epigenetic changes that occur in tumor cells, it can help to identify new promising biomarkers, and to develop innovative strategies for the diagnosis and early treatment strategies of pediatric spinal cord astrocytomas. Furthermore, because of the rarity of these tumors, collaborative, multicenter investigations will be required to integrate genetics information toward the design of more effective treatment options and in clinical decision making.

\section{Conflicts of Interest}

The Authors disclose no potential conflicts of interest regarding this study.

\section{Authors' Contributions}

$\mathrm{CM}$ and FG conceptualized and performed molecular experiments; RB and FN executed Array-CGH analysis; FM, ES and RB carried out bioinformatics analysis; MP, IM and RP collected and analyzed clinical data; SC wrote the manuscript; all authors corrected and approved the final draft.

\section{Acknowledgements}

This research was supported by the Italian Ministry of Education, University and Research (MIUR): Dipartimenti di Eccellenza Program (2018-2022) - Dept. of Biology and Biotechnology "L. Spallanzani”, University of Pavia (to SC). RC was supported by a Grant of the Italian Ministry of Education, University and Research (MIUR) to the Department of Molecular Medicine of the University of Pavia under the initiative "Dipartimenti di Eccellenza (2018-2022)".

\section{References}

1 Burkhard C, Di Patre PL, Schüler D, Schüler G, Yaşargil MG, Yonekawa Y, Lütolf UM, Kleihues $\mathrm{P}$ and Ohgaki $\mathrm{H}$ : A population-based study of the incidence and survival rates in patients with pilocytic astrocytoma. J Neurosurg 98(6): 11701174, 2003. PMID: 12816259. DOI: 10.3171/jns.2003.98.6.1170

2 Bond KM, Hughes JD, Porter AL, Orina J, Fang S and Parney IF: Adult pilocytic astrocytoma: An institutional series and systematic literature review for extent of resection and recurrence. World Neurosurg 110: 276-283, 2018. PMID: 29180079. DOI: 10.1016/j.wneu.2017.11.102

3 Jiang Y, Lv L, Yin S, Zhou P and Jiang S: Primary spinal pilocytic astrocytoma: Clinical study with long-term follow-up in 16 patients and a literature review. Neurosurg Rev 2019. PMID: 31098788. DOI: 10.1007/s10143-019-01109-0

4 Crabtree KL and Arnold PM: Spinal seeding of a pilocytic astrocytoma in an adult, initially diagnosed 18 years previously. Pediatr Neurosurg 46(1): 66-70, 2010. PMID: 20516744. DOI: $10.1159 / 000315320$

5 Horger M, Ritz R, Beschorner R, Fenchel M, Nägele T, Danz S and Ernemann U: Spinal pilocytic astrocytoma: MR imaging findings at first presentation and following surgery. Eur J Radiol 79(3): 389-399, 2011. PMID: 20478675. DOI: 10.1016/ j.ejrad.2010.04.024 
6 Zorlu F, Selek U, Akyuz C, Ozturk A, Soylemezoglu F and Akalan N: Spinal seeding of a pilocytic astrocytoma following multiple subtotal resections. Pediatr Neurosurg 41(5): 248-252, 2005. PMID: 16195677 . DOI: $10.1159 / 000087483$

7 Rashad S, Elwany A and Farhoud A: Surgery for spinal intramedullary tumors: technique, outcome and factors affecting resectability. Neurosurg Rev 41(2): 503-511, 2018. PMID: 28717891. DOI: $10.1007 / \mathrm{s} 10143-017-0879-\mathrm{z}$

8 Choi GH, Oh JK, Kim TY, You NK, Lee HS, Yoon DH, Ha Y, Yi S, Kim DS, Choi JU and Kim KN: The clinical features and surgical outcomes of pediatric patients with primary spinal cord tumor. Childs Nerv Syst 28(6): 897-904, 2012. PMID: 22447490. DOI: $10.1007 / \mathrm{s} 00381-012-1718-8$

9 Ebner FH, Schittenhelm J, Roser F, Scheel-Walter H, Tatagiba $\mathrm{M}$ and Schuhmann MU: Management of holocord pilocytic astrocytomas in children and adolescents: an update. Pediatr Neurosurg 48(3): 133-140, 2012. PMID: 23429240. DOI: $10.1159 / 000345593$

10 Harraher CD, Vogel $\mathrm{H}$ and Steinberg GK: Spinal pilocytic astrocytoma in an elderly patient. World Neurosurg 79(5-6): 799.e7799.e9, 2013. PMID: 22120566. DOI: 10.1016/j.wneu.2011.10.033

11 Philipson MR, Timothy J, Chakrobarthy A and Towns G: Pilocytic astrocytoma of a spinal nerve root. Case report. J Epidemiology 97(1 Suppl): 110-112, 2002. PMID: 12120632. DOI: $10.3171 / \mathrm{spi} .2002 .97 .1 .0110$

12 Rangwala SD, Oh G, Barks AL and Nikas DC: Intramedullary Thoracic Spine Astrocytoma Presenting as Hydrocephalus in an Infant: A Case Report. Pediatr Neurosurg 52(5): 327-330, 2017. PMID: 28848162. DOI: 10.1159/000479323

13 Orillac C, Thomas C, Dastagirzada Y, Hidalgo ET, Golfinos JG, Zagzag D, Wisoff JH, Karajannis MA and Snuderl M: Pilocytic astrocytoma and glioneuronal tumor with histone H3 K27M mutation. Acta Neuropathol Commun 4(1): 84, 2016. PMID: 27519587. DOI: $10.1186 / \mathrm{s} 40478-016-0361-0$

14 Shankar GM, Lelic N, Gill CM, Thorner AR, Van Hummelen P, Wisoff JH, Loeffler JS, Brastianos PK, Shin JH, Borges LF, Butler WE, Zagzag D, Brody RI, Duhaime AC,Taylor MD Hawkins CE, Louis DN, Cahill DP, Curry WT and Meyerson M: BRAF alteration status and the histone H3F3A gene K27M mutation segregate spinal cord astrocytoma histology. Acta Neuropathol 131: 147-150, 2016. PMID: 26487540. DOI: 10.1007/s00401-015-1492-2

15 Karsy M, Guan J, Sivakumar W, Neil JA, Schmidt MH and Mahan MA: The genetic basis of intradural spinal tumors and its impact on clinical treatment. Neurosurg Focus 39(2): E3, 2015. PMID: 26235020. DOI: 10.3171/2015.5.FOCUS15143

16 Collins VP, Jones DT and Giannini C: Pilocytic astrocytoma: pathology, molecular mechanisms and markers. Acta Neuropathol 129(6): 775-788, 2015. PMID: 25792358. DOI: 10.1007/s00401-015-1410-7

17 Sollfrank L, Lettmaier S, Erdmann M and Uslu U: Panniculitis Under Successful Targeted Inhibition of the MAPK/ERK Signaling Pathway in a Patient With BRAF V600E-mutated Spindle Cell Oncocytoma of the Pituitary Gland. Anticancer Res 39(7): 3955-3959, 2019. PMID: 31262927. DOI: 10.21873/ anticanres.13549

18 Davidson NM, Majewski IJ and Oshlack A: JAFFA: High sensitivity transcriptome-focused fusion gene detection. Genome Med 7(1): 43, 2015. PMID: 26019724. DOI: 10.1186/s13073$015-0167-\mathrm{x}$
19 Kim D and Salzberg SL: TopHat-Fusion: an algorithm for discovery of novel fusion transcripts. Genome Biol 12(8): R72, 2011. PMID: 21835007. DOI: 10.1186/gb-2011-12-8-r72

20 Ge H, Liu K, Juan T, Fang F, Newman M and Hoeck W: FusionMap: Detecting fusion genes from next-generation sequencing data at base-pair resolution. Bioinformatics 27(14): 1922-1928, 2011. PMID: 21593131. DOI: 10.1093/bioinformatics/ btr310

21 Mitelman Database of Chromosome Aberrations and Gene Fusions in Cancer. Mitelman F, Johansson B and Mertens F (Eds.), 2019. https://mitelmandatabase.isb-cgc.org/

22 Tate JG, Bamford S, Jubb HC, Sondka Z, Beare DM, Bindal N, Boutselakis H, Cole CG, Creatore C, Dawson E, Fish P, Harsha B, Hathaway C, Jupe SC, Kok CY, Noble K, Ponting L, Ramshaw CC, Rye CE, Speedy HE, Stefancsik R, Thompson SL, Wang S, Ward S, Campbell PJ and Forbes SA: COSMIC: the Catalogue Of Somatic Mutations In Cancer. Nucleic Acids Res 47(D1): D941-D947, 2019. PMID: 30371878. DOI: 10.1093/nar/gky1015

23 Kim P, Yoon S, Kim N, Lee S, Ko M, Lee H, Kang H, Kim J and Lee S: ChimerDB 2.0 A knowledgebase for fusion genes updated. Nucleic Acids Res 38: D81-D85, 2010. PMID: 19906715. DOI: $10.1093 /$ nar/gkp982

24 Weatherall E and Willmott GR: Applications of tunable resistive pulse sensing. Analyst 140(10): 3318-3334, 2015. PMID: 25738184. DOI: $10.1039 / \mathrm{c} 4 \mathrm{an} 02270 \mathrm{j}$

25 Chandrashekar DS, Bashel B, Balasubramanya SAH, Creighton CJ, Rodriguez IP, Chakravarthi BVSK and Varambally S: UALCAN: A portal for facilitating tumor subgroup gene expression and survival analyses. Neoplasia 19(8): 649-658, 2017. PMID: 28732212. DOI: 10.1016/j.neo.2017.05.002

26 Sun W, Zhang L, Yan R, Yang Y and Meng X: LncRNA DLX6AS1 promotes the proliferation, invasion, and migration of nonsmall cell lung cancer cells by targeting the miR-27b-3p/GSPT1 axis. Onco Targets Ther 12: 3945-3954, 2019. PMID: 31190891. DOI: $10.2147 /$ OTT.S196865

27 Konovalov NA, Asyutin DS, Shayhaev EG, Kaprovoy SV and Timonin SY: Molecular biomarkers of brain and spinal cord astrocytomas. Acta Naturae 11(2): 17-27, 2019. PMID: 31413876. DOI: $10.32607 / 20758251-2019-11-2-17-27$

28 Dressen A, Abbas AR, Cabanski C, Reeder J, Ramalingam TR, Neighbors M, Bhangale TR, Brauer MJ, Hunkapiller J, Reeder J, Mukhyala K, Cuenco K, Tom J, Cowgill A, Vogel J, Forrest WF, Collard HR, Wolters PJ, Kropski JA, Lancaster LH, Blackwell TS, Arron JR and Yaspan BL: Analysis of proteinaltering variants in telomerase genes and their association with MUC5B common variant status in patients with idiopathic pulmonary fibrosis: a candidate gene sequencing study. Lancet Respir Med 6(8): 603-614, 2018. PMID: 29891356. DOI: $10.1016 / \mathrm{S} 2213-2600(18) 30135-8$

29 Liu B, Hu FF, Zhang Q, Hu H, Ye Z, Tang Q and Guo AY: Genomic landscape and mutational impacts of recurrently mutated genes in cancers. Mol Genet Genomic Med 6(6): 910923, 2018. PMID: 30107644. DOI: $10.1002 / \mathrm{mgg} 3.458$

30 Duan J, Zhang H, Li S, Wang X, Yang H, Jiao S and Ba Y: The role of miR-485-5p/NUDT1 axis in gastric cancer. Cancer Cell Int 17: 92, 2017. PMID: 29075149. DOI: 10.1186/s12935-0170462-2

31 Deryugina EI, Zajac E, Zilberberg L, Muramatsu T, Joshi G, Dabovic B, Rifkin D and Quigley JP: LTBP3 promotes early 
metastatic events during cancer cell dissemination. Oncogene 37(14): 1815-1829, 2018. PMID: 29348457. DOI: 10.1038/ s41388-017-0075-1

32 Yeste-Velasco M, Mao X, Grose R, Kudahetti SC, Lin D, Marzec J, Vasiljević N, Chaplin T, Xue L, Xu M, Foster JM, Karnam SS, James SY, Chioni AM, Gould D, Lorincz AT, Oliver RT, Chelala C, Thomas GM, Shipley JM, Mather SJ, Berney DM, Young BD and Lu YJ: Identification of ZDHHC14 as a novel human tumor suppressor gene. J Pathol 232(5): 566-577, 2014. PMID: 24407904. DOI: 10.1002/path.4327

33 Oo HZ, Sentani K, Sakamoto N, Anami K, Naito Y, Uraoka N, Oshima T, Yanagihara K, Oue N and Yasui W: Overexpression of ZDHHC14 promotes migration and invasion of scirrhous type gastric cancer. Oncol Rep 32: 403-410, 2014. PMID: 24807047. DOI: $10.3892 /$ or.2014.3166

34 Monoranu CM, Huang B, Zangen IL, Rutkowski S, Vince GH, Gerber NU, Puppe B and Roggendorf W: Correlation between 6q25.3 deletion status and survival in pediatric intracranial ependymomas. Cancer Genet Cytogenet 182(1): 18-26, 2008. PMID: 18328946. DOI: 10.1016/j.cancergencyto.2007.12.008

35 Yang J, Ye Z, Mei D, Gu H and Zhang J: Long noncoding RNA DLX6-AS1 promotes tumorigenesis by modulating miR-4975p/FZD4/FZD6/Wnt/ $\beta$-catenin pathway in pancreatic cancer. Cancer Manag Res 11: 4209-4221, 2019. PMID: 31118816. DOI: $10.2147 / C M A R . S 194453$

36 Zhou FR, Pan ZP, Shen F, Huang LQ, Cui JH, Cai K and Guo XL: Long noncoding RNA DLX6-AS1 functions as a competing endogenous RNA for miR-577 to promote malignant development of colorectal cancer. Eur Rev Med Pharmacol Sci 23(9): 3742-3748, 2019. PMID: 31115000. DOI: 10.26355/eurrev_201905_17800

37 Zhao J and Liu HR: Down-regulation of long noncoding RNA DLX6-AS1 defines good prognosis and inhibits proliferation and metastasis in human epithelial ovarian cancer cells via Notch signaling pathway. Eur Rev Med Pharmacol Sci 23(8): 3243-3252, 2019. PMID: 31081076. DOI: 10.26355/eurrev_201904_17684
38 Sun W, Zhang L, Yan R Yang Y and Meng X: LncRNA DLX6AS1 promotes the proliferation, invasion, and migration of nonsmall cell lung cancer cells by targeting the miR-27b-3p/GSPT1 axis. Onco Targets Ther 12: 3945-3954, 2019. PMID: 31190891. DOI: $10.2147 / O T T . S 196865$

$39 \mathrm{Fu}$ X, Tian Y, Kuang W, Wen S and Guo W: Long non-coding RNA DLX6-AS1 silencing inhibits malignant phenotypes of gastric cancer cells. Exp Ther Med 17(6): 4715-4722, 2019. PMID: 31105791. DOI: 10.3892/etm.2019.7521

$40 \mathrm{Wu}$ DM, Zheng ZH, Zhang YB, Fan SH, Zhang ZF, Wang YJ, Zheng YL and Lu J: Down-regulated lncRNA DLX6-AS1 inhibits tumorigenesis through STAT3 signaling pathway by suppressing CADM1 promoter methylation in liver cancer stem cells. J Exp Clin Cancer Res 38(1): 237, 2019. PMID: 31171015. DOI: 10.1186/s13046-019-1239-3

41 Koga K, Matsumoto K, Akiyoshi T, Kubo M, Yamanaka N, Tasaki A, Nakashima H, Nakamura M, Kuroki S, Tanaka M and Katano M: Purification, characterization and biological significance of tumor-derived exosomes. Anticancer Res 25(6A): 3703-3707, 2005. PMID: 16302729.

42 Haug BH, Hald ØH, Utnes P, Roth SA, Løkke C, Flægstad T and Einvik C: Exosome-like Extracellular Vesicles from MYCNamplified Neuroblastoma Cells Contain Oncogenic miRNAs. Anticancer Res 35(5): 2521-2530, 2015. PMID: 25964525.

Received November 22, 2019 Revised December 4, 2019 Accepted December 10, 2019 